\title{
A PRELIMINARY ANALYSIS OF NATURAL DISASTERS, RECENT TRENDS AND FUTURE PROSPECTS IN PAKISTAN AND BORDERING COUNTRIES: A REVIEW
}

\author{
Sana Ullah \\ School of Information and Software Engineering, University of Electronic Science and Technology of China (UESTC), Chengdu, P. R. China. \\ *Corresponding Author Email: Sanaullah.cs@fuuast.edu.pk
}

This is an open access article distributed under the Creative Commons Attribution License, which permits unrestricted use, distribution, and reproduction in any medium, provided the original work is properly cited.

\section{ARTICLE DETAILS}

\section{Article History:}

Received 21 August 2019

Accepted 23 September 2019

Available online 11 October 2019

\begin{abstract}
In the last several years, Pakistan has faced great challenges and serious threat from extensive natural disasters such as earthquake, landslide and flood. Different disaster management strategies, policies and technological based systems have been utilized in disaster, pre-disaster and post disaster to diminish its effects on surrounding and human life. The analysis of disaster pattern plays vital role in crisis management, disaster response and evacuation planning. It increases public awareness about disasters and also improve both planning and investigation. In this study, different disasters (Earthquake, flood and landslide) are analyzed and observed historical record of sixteen years (2000-2016) in Pakistan and also focus on comparative study of these disasters with their neighbor countries. The occurrences of different disasters and their impacts on human life have been analyzed. Secondary objective is the comparative analysis of different disasters, their occurrence, death and total affected victim of Pakistan with their neighbor countries. The analyzed outcome patterns can be helpful in pre disaster, disaster and post-disaster activities to trim down lives losses, economical losses and damages due to the occurrences of disasters.
\end{abstract}

\section{KEYWORDS}

Natural disasters, Vulnerability, Prevention, Disaster management, Disaster effects, Pre-disaster, Post disaster, disaster in Pakistan.

\section{INTRODUCTION}

Pakistan is considered as 36th largest nation by total area. It shares its boundaries with the India, Afghanistan, Iran and china. It lies between Longitudes of $620 \mathrm{E} \& 750 \mathrm{E}$ and Latitudes of $240 \mathrm{~N}$ and $370 \mathrm{~N}$, having $796,095 \mathrm{~km}$ total land area. Due to varieties of physical and natural surroundings, Pakistan is facing different natural disasters such as floods, earthquakes, landslides and man-made disasters like road accidents, industrial accidents, fire and terrorism. In 2003, world disaster report declared that due to flood 6037 people lost their lives and 8,989,631 were affected in the range of 1993 to 2002 . The world history confirms that Pakistan is more exposed country to natural disasters. National disaster management authority is responsible for regulating, coordination and training of public and also to develop diverse recovery systems using latest technologies to decrease the natural disasters effects [1].

According to national disaster management authority (NDMA), the Pakistan suffers a loss of around $\$ 800$ million every year. Disaster is a sudden unfriendly or terrible occasion which causes extraordinary harm to people, plants and individuals. Disaster happens quickly, promptly and unpredictably. These occasions which happen irritate normal natural procedures to make disaster to human culture for example, sudden structural developments prompting to tremor and volcanic emissions, preceded with dry conditions prompting to delayed dry spells, surges, barometrical unsettling influences, crash of divine bodies etc. Natural disaster is the impact of a natural hazard (e.g., Earthquake, flood, tornado tropical storm, volcanic emission). It prompts to financial, ecological and human misfortunes [2,3].

Pakistan is very exposed to calamities which are created by climate change. Particularly it is inclined to surges and dry seasons. Dust storms, clean tempests, small scale deluges, typhoons and tidal waves are extra dangers. As of late Pakistan has seen a few extreme occasions, bringing about significant death toll and property and creating disorder in a few problem areas. The good countries are especially powerless against
Glacier Lake Outburst Floods (GLOF). Pakistan has 5218 icy masses and 2420 lakes, of which 50 are risky and may bring about flooding in the fields of Punjab and Sindh. The exceptionally powerless Indus delta confronts perils from ocean interruption and ocean rise (Kazmi). Natural disaster caused due to the change of meteorological, land or organic starting point, which is outside our ability to control. Disaster Mitigation by vulnerability extent to which a group, structure, administrations or geographic range is probably going to be harmed or upset by a specific peril, which is inside our control by using innovation in technology. The risk can be reduced by the integration of different sensors and IT technology in a form of Early warning systems and Information sharing system before and after the occurrences of natural disasters $[1,4]$.

The core aim of study is to conduct preliminary analysis of historical sixteen years of disaster data to find out the occurrences of different disasters and their impacts on human life like occurrences rate and impact on human life. In addition, the different disasters patterns which have been occurred in Pakistan. Alternative objective is to compare disasters occurred in Pakistan with neighbor countries. The occurrences of disasters and as well its impacts in Pakistan have been discussed along with comparing it neighboring countries for pattern comparison. It describes a number of spatial disaster patterns and trends over time in Pakistan. This analysis could be a useful input into various components of disaster risk management, such as risk assessment, disaster profiling, localized and targeted disaster response interventions and early and longterm recovery strategies. Different trends are observed in all disasters in the period of sixteen years of the study (2000-2016), so as to make responsible authorities alert about the coming expected disaster to make planning, strategies and recovery strategies. Historical data related to disaster is the cornerstone for disaster management because future prediction and planning depend on it.

The data about different disasters have been collected from government agencies, the parallel data collection systems of PDMA and NDMA in Pakistan. Furthermore, the analyzed data of Pakistan and other target 
countries is also taken from an open source media [5]. For the analysis of the said data, ANNOVA model has been utilized. The main aim of the research paper is to analyze different disasters data of the mentioned interval and as well to find the specific occurring patterns in each disaster. Furthermore, it will suggest an alert to the disaster management authorities to plan some preventive strategies for the upcoming disasters.

\section{MATERIALS AND METHODS}

In this paper, an ANNOVA statistical methodology has been used to analyze different disasters, disasters effects on surrounding and disaster patterns compare with neighboring countries. The proposed approach based on Ho null hypothesis and $\mathrm{H} 1$ alternate hypothesis is to measure the p-value of the hypothesis with respect to the existing previous sixteenyear disasters data. One-way ANOVA model is used to analyze the mentioned hypotheses by utilization of these normality and homogeneity of variances tests. On the basis of measured value, the hypothesis will either be accepted or rejected. For the quantitative analysis of the understudy disaster types, an ANOVA (Analysis of Variance) model utilized an intervals of sixteen years of disasters.

In the analysis, three types of disasters have been analyzed (Earthquake, flood, landslide). The analyzed data is from 2000 to 2016 (Sixteen years) and the combine occurrences of all types of disasters are twenty-five times. The Table 1 shows the occurrences of different disasters year-wise. In 2006, 2009, 2010, 2012 and 2013 the occurrence rate is three times while deaths against these years are $12 \%$. In 2005 the occurrence rate is two times and a death against this year is $8 \%$. In 2002, 2003, 2004, 2005, $2007,2011,2014$ and 2016 the occurrence rate is one times and deaths against these years are $4 \%$.

Table 1: The occurrences of different disasters year-wise

\begin{tabular}{||l|l|l|l|l|}
\hline Year & Frequency & Percent & Valid Percent & Cumulative Percent \\
\hline 2002 & 1 & 4.0 & 4.0 & 4.0 \\
\hline 2003 & 1 & 4.0 & 4.0 & 8.0 \\
\hline 2004 & 1 & 4.0 & 4.0 & 12.0 \\
\hline 2005 & 1 & 4.0 & 4.0 & 16.0 \\
\hline 2006 & 3 & 12.0 & 12.0 & 28.0 \\
\hline 2007 & 1 & 4.0 & 4.0 & 32.0 \\
\hline 2009 & 3 & 12.0 & 12.0 & 44.0 \\
\hline 2010 & 3 & 12.0 & 12.0 & 56.0 \\
\hline 2011 & 1 & 4.0 & 4.0 & 60.0 \\
\hline 2012 & 3 & 12.0 & 12.0 & 72.0 \\
\hline 2013 & 3 & 12.0 & 12.0 & 84.0 \\
\hline 2014 & 1 & 4.0 & 4.0 & 88.0 \\
\hline 2015 & 2 & 8.0 & 8.0 & 96.0 \\
\hline 2016 & 1 & 4.0 & 4.0 & 100.0 \\
\hline Total & 25 & 100.0 & 100.0 & --- \\
\hline
\end{tabular}

In these sixteen years, the occurrence rate of earthquake and landslide are same for both which is six times, while the total occurrence of flood is thirteen times which is considerably more severe than all other years.

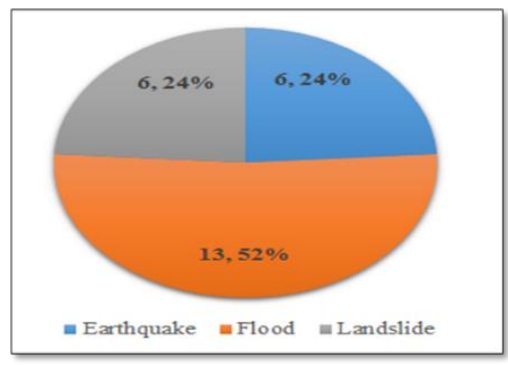

By comparing the total deaths of the three types of disasters (Earthquake, Flood, Landslides), the Null and alternate hypothesis are

\section{$\boldsymbol{H}_{o}$ : Average numbers of deaths in three groups of disaster are same}

$$
H_{o}: \mu_{1}=\mu_{2}=\mu_{3}
$$

\section{$H_{1}$ : Not all the three groups having same average}

Before conducting the hypothesis test by one factor ANOVA, the number of assumptions for the given samples is checked. Test of Normality and homogeneity of variance test are conducted for one-way ANOVA. Results of normality are given in Table 2.
Table 2: Tests of Normality

\begin{tabular}{|c|c|c|c|c|c|c|c|}
\hline & \multirow{2}{*}{$\begin{array}{l}\text { Type } \\
\text { Coded }\end{array}$} & \multicolumn{3}{|c|}{ Kolmogorov-Smirnova } & \multicolumn{3}{|c|}{ Shapiro-Wilk } \\
\hline & & Statistic & df & Sig. & Statistic & df & Sig. \\
\hline \multirow{3}{*}{$\begin{array}{l}\text { Total } \\
\text { deaths }\end{array}$} & 1 & .324 & 6 & .048 & .839 & 6 & .128 \\
\hline & 2 & .259 & 13 & .017 & .854 & 13 & .032 \\
\hline & 3 & .261 & 6 & $.200^{*}$ & .860 & 6 & 188 \\
\hline
\end{tabular}

*. This is a lower bound of the true significance.

a. Lilliefors Significance Correction

At $1 \%$ level of significance, Kolmogorov-Smirnov and Shapiro test are insignificant; the data in these three groups are normally distributed.

Table 3 shows the results of Levene's test for the homoscedasticity pvalue which is 0.117 is more than 0.01 as well as by 0.05 therefore the three groups having the same variances. i.e.

$$
H_{o}: \sigma_{1}^{2}=\sigma_{2}^{2}=\sigma_{3}^{2}
$$

Table 4 shows the results of one way ANOVA between groups it indicates that the insignificant results means the null hypothesis is accepted at $1 \%$ and at $5 \%$. The three type of disasters having same average total deaths. Post hoc test is not necessary, because the null hypothesis is accepted

$$
H_{o}: \mu_{1}=\mu_{2}=\mu_{3}
$$

Table 3: Test of Homogeneity of Variances

Total deaths

\begin{tabular}{|l|l|l|l|}
\hline Levene Statistic & df1 & df2 & Sig. \\
\hline 2.373 & 2 & 22 & .117 \\
\hline
\end{tabular}

Table 4: ANOVA

Total deaths

\begin{tabular}{|l|l|l|l|l|l|}
\hline & Sum of Squares & Df & Mean Square & F & Sig. \\
\hline $\begin{array}{l}\text { Between } \\
\text { Groups }\end{array}$ & 72448.884 & 2 & 36224.442 & 2.529 & .103 \\
Within & 315123.756 & 22 & 14323.807 & & \\
Groups & 387572.640 & 24 & & & \\
Total & 340 & & & \\
\hline
\end{tabular}

\subsection{Pakistan Disaster Profile}

Following trends and spatial distribution patterns aim to provide an overview and analysis of all natural disasters occurrences and their effects like total death, injured, affected peoples, homeless persons in the previous sixteen years in Pakistan. Based on current trends, future occurrences of disasters can be predicted.

\subsection{Analysis of flood in Pakistan}

Occurrences of flood in Pakistan Figure 1 show occurrences of Flood in Pakistan from 2000 to 2016. By observing the whole mentioned period of occurrences of Flood shows that in years 2005 and 2016 Flood occurred seven times in each year respectively. In 2007 and 2015 Flood occurrence were recorded six times in each year. In 2005 it occurred five times. In 2010 occurred four times. In 2002, 2003, 2008 and 2009 the occurrences were three times in each year. In 2004 and 2013 occurrences was two times in each year. In 2001, 2011 and 2014 occurrences was one times in each year respectively.

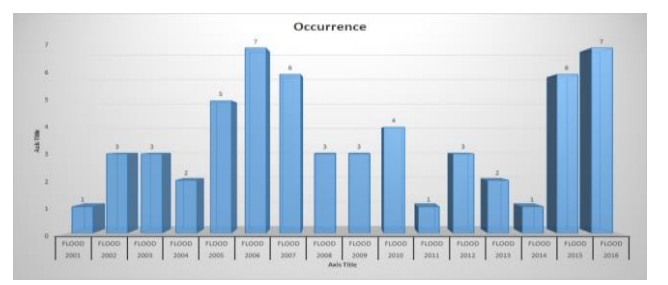

Figure 1: Occurrences of Flood in Pakistan from 2000 to 2016

\subsection{Total affected people in Pakistan due to Flood}

Figure 2 shows the number of people affected in the mentioned period due to Flood in Pakistan. By observing the whole mentioned period of Flood 
occurrences shows that 2005(7523073 people) and 2011 (5400000 people), but 2010 is the most affected (20360550 peoples) in flood.

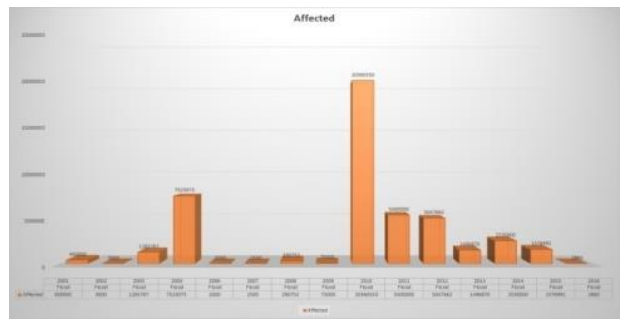

Figure 2: Proportion of Flood Affected

\subsection{Total deaths in Pakistan due to Flood}

Figure 3 shows the total deaths occurred in Pakistan due to Flood from 2000 to 2016. By analyzing the overall mentioned period shows that in 2005(636 deaths) and in 2011 (509 deaths) but 2010 (2113 deaths) is considerable more damaged year.

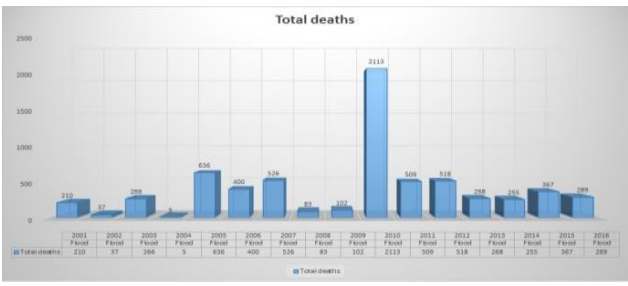

Figure 3: Proportions of Flood Deaths

\subsection{Analysis of Earthquake in Pakistan}

Figure 4 shows Occurrences of Earthquake in period from 2000 to 2016 in Pakistan. Analysis shows that in 2001, 2004,2005,2008,2011 and in 2016 Earthquake occurred only once in each year respectively. It occurred twice in 2015. In 2002 and 2013 occurrences were recorded three times in each year.

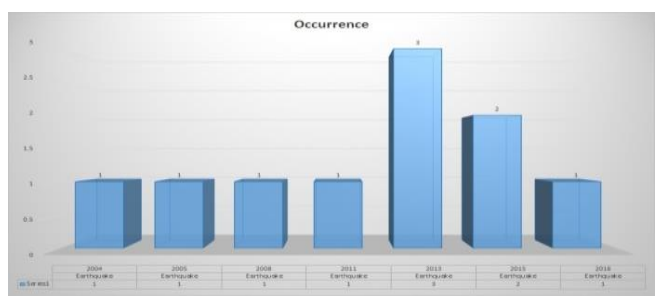

Figure 4: Occurrences of Earthquake

\subsection{Total affected people in Pakistan due to Earthquake}

Figure 5 shows the number of people affected community of Pakistan due to Flood from 2000 to 2016. By observing the whole mentioned period of Flood occurrences shows that 2005(5128309 people) is the most affected as compare to other years.

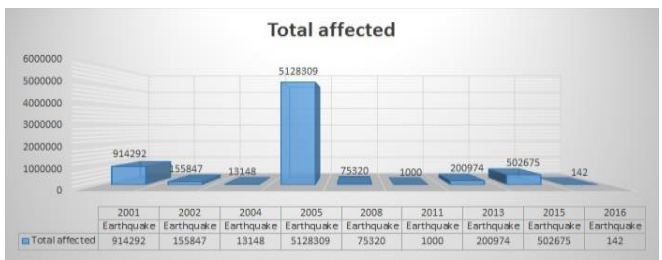

Figure 5: People affected community of Pakistan due to Flood from 2000 to 2016

\subsection{Total deaths in Pakistan due to Earthquake}

Figure 6 shows the number of deaths due to Earthquake in Pakistan from 2000 to 2016. By observing the period of sixteen years show that in 2005 (73338 deaths) have more deaths as compare to other years.

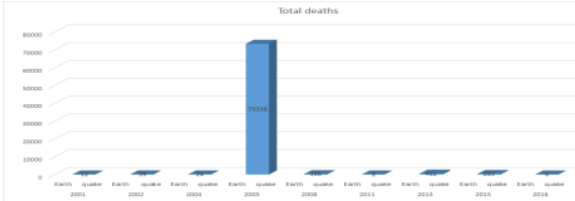

Figure 6: Total deaths of Earthquake

\subsection{Analysis of Landslide in Pakistan}

Figure 7 shows Occurrences of Landslide in Pakistan from 2000 to 2016 Analysis shows that in years 2003, 2005 and 2006 landslides occurred once in each year. In 2001, 2010 and 2012 the occurrences rate was twice, while in 2007 the occurrences rate is three times which most affected year is as compare to all other.

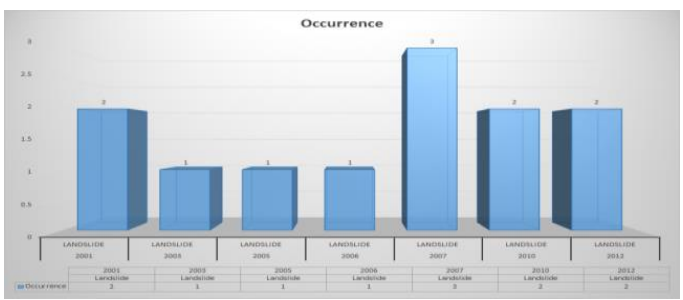

Figure 7: Occurrences of Landslide

\subsection{Total affected people in Pakistan due to Landslide}

Figure 8 shows the number of people affected community of Pakistan due to Flood from 2000 to 2016. By observing the whole mentioned period of Flood occurrences shows that 2010(30405 people) is the most affected as compare to other years.

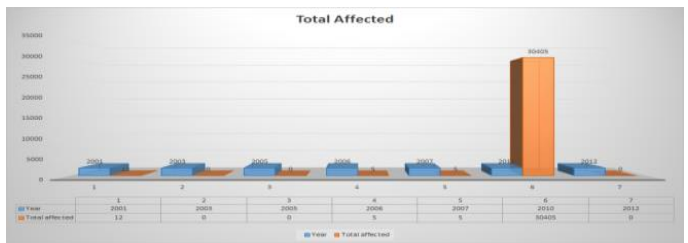

Figure 8: Number of people affected community of Pakistan due to Flood from 2000 to 2016

\section{$2.10 \quad$ Total deaths in Pakistan due to Landslide}

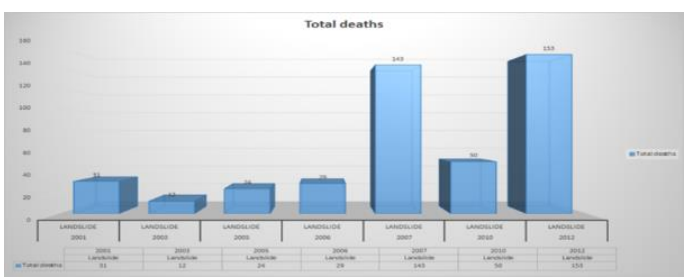

Figure 9: Total deaths of Landslides

Figure 9 shows the number deaths due to Landslide in Pakistan from 2000 to 2016. By investigating the deaths due to landslide in the period of sixteen years, the analysis that 2003(12 deaths), 2005(24 deaths), 2006(29 deaths), 2001(31 deaths), 2010(50 deaths), while in 2007 (143 deaths) and 2012 (153 deaths) more deaths were occurred as compare to other years.

\section{CASE STUDIES}

\subsection{Case study-1}

India is considered as the world's most disaster affected nation in the world. In the same way as other different nations in this region, India is under attack by different sorts of disaster types every year, for example, earthquakes, floods, cyclone, landslide and storm etc. A large number of persons are affected each year. On the basis of preliminary analysis of historical data, over the past sixteen years, rate of occurrence of flood (17) is higher than earthquake, landslides and storm. Rate of total deaths over earthquake (16389) is higher than flood, landslides and storm. Rate of affected people over flood (33206000) is higher than earthquake, landslides and storm as shown as Table 5.

\begin{tabular}{|l|l|l|l|l|}
\hline Year & $\begin{array}{l}\text { Disaster } \\
\text { type }\end{array}$ & Occurrence & $\begin{array}{l}\text { Total } \\
\text { deaths }\end{array}$ & $\begin{array}{l}\text { Total } \\
\text { affected }\end{array}$ \\
\hline 2000 & Flood & 6 & 2086 & 50386051 \\
\hline 2000 & Landslide & 3 & 187 & 7038 \\
\hline 2001 & Earthquake & 1 & 20005 & 6321812 \\
\hline 2001 & Flood & 9 & 581 & 20610040 \\
\hline 2001 & Landslide & 3 & 98 & --- \\
\hline 2001 & Storm & 3 & 99 & 27000 \\
\hline
\end{tabular}




\begin{tabular}{|l|l|l|l|l|}
\hline 2002 & Earthquake & 1 & 2 & 200 \\
\hline 2002 & Flood & 6 & 735 & 42008250 \\
\hline 2002 & Storm & 4 & 144 & 15250 \\
\hline 2003 & Flood & 6 & 452 & 7564545 \\
\hline 2003 & Landslide & 1 & 25 & -- \\
\hline 2003 & Storm & 7 & 164 & 531314 \\
\hline 2004 & Earthquake & 1 & 16389 & 654512 \\
\hline 2004 & Flood & 6 & 1348 & 33206000 \\
\hline 2005 & Earthquake & 1 & 1309 & 156622 \\
\hline 2005 & Flood & 17 & 2129 & 28281571 \\
\hline 2005 & Landslide & 2 & 262 & 5020 \\
\hline 2006 & Flood & 17 & 1194 & 7234178 \\
\hline 2007 & Flood & 16 & 2051 & 38143008 \\
\hline 2008 & Flood & 8 & 1590 & 13989018 \\
\hline 2008 & Landslide & 1 & 37 & --- \\
\hline 2009 & Flood & 6 & 1500 & 5986008 \\
\hline 2009 & Landslide & 2 & 55 & --- \\
\hline 2010 & Flood & 8 & 690 & 3772408 \\
\hline 2010 & Landslide & 1 & 17 & --- \\
\hline 2011 & Earthquake & 1 & 112 & 575200 \\
\hline 2011 & Flood & 7 & 608 & 12004069 \\
\hline 2012 & Flood & 6 & 279 & 4210860 \\
\hline 2013 & Earthquake & 1 & 3 & 59350 \\
\hline 2013 & Flood & 5 & 6453 & 3419473 \\
\hline 2013 & Storm & 5 & 106 & 13230004 \\
\hline 2014 & Flood & --- & 622 & 5222500 \\
\hline 2014 & Landslide & 1 & 151 & 200 \\
\hline 2015 & Earthquake & 3 & 98 & 570 \\
\hline 2015 & Flood & 10 & 839 & 16413459 \\
\hline 2015 & Landslide & 1 & 3 & 9000 \\
\hline 2016 & Earthquake & 1 & 8 & 10808 \\
\hline 2016 & Flood & 8 & 295 & 2488097 \\
\hline 2016 & Landslide & 2 & 20 & 5 \\
\hline & & & & \\
\hline
\end{tabular}

\subsection{Case study-2}

Natural disaster events include earthquake, flooding, heavy rainfall, landslides and heavy snowfall are also recorded by Afghanistan due to which Afghanistan is considered as disaster affected nation in the world. Afghanistan is located in a zone of high-seismic area of world where chances of the occurrences of natural disaster is higher than other nations. Number of persons was affected by these natural disasters. On the basis of preliminary analysis of historical data, over the past sixteen years, rate of occurrence of flood (9) is higher than earthquake and landslides. Rate of total deaths over landslide (324) is higher than flood and earthquake. Rate of affected people over flood (150135) is higher than earthquake and landslides as show in Table-6.

\begin{tabular}{|l|l|l|l|l|l|}
\hline Year & $\begin{array}{l}\text { Disaster } \\
\text { type }\end{array}$ & Occurrence & $\begin{array}{l}\text { Total } \\
\text { deaths }\end{array}$ & Injured & $\begin{array}{l}\text { Total } \\
\text { affected }\end{array}$ \\
\hline 2001 & Earthquake & 2 & 4 & 20 & 270 \\
\hline 2002 & Earthquake & 3 & 1200 & 1391 & 100891 \\
\hline 2002 & Flood & 4 & 81 & --- & 5545 \\
\hline 2002 & Landslide & 1 & 5 & --- & 400 \\
\hline 2003 & Earthquake & 1 & 1 & 1 & 1001 \\
\hline 2003 & Flood & 8 & 136 & 3 & 3753 \\
\hline 2004 & Earthquake & 1 & 2 & 40 & 1040 \\
\hline 2004 & Flood & 2 & 16 & --- & 4500 \\
\hline 2005 & Earthquake & 2 & 6 & 1 & 501 \\
\hline
\end{tabular}

\begin{tabular}{|l|l|l|l|l|l|}
\hline 2005 & Flood & 9 & 295 & 43 & 18318 \\
\hline 2006 & Earthquake & 1 & 1 & --- & 935 \\
\hline 2006 & Flood & 7 & 282 & 185 & 32975 \\
\hline 2006 & Landslide & 2 & 28 & --- & 300000 \\
\hline 2007 & Flood & 7 & 296 & 20 & 30255 \\
\hline 2008 & Flood & 1 & & --- & 1180 \\
\hline 2009 & Earthquake & 1 & 22 & 59 & 3309 \\
\hline 2009 & Flood & 3 & 69 & 16 & 62516 \\
\hline 2010 & Earthquake & 1 & 11 & 70 & 1070 \\
\hline 2010 & Flood & 2 & 135 & --- & 45000 \\
\hline 2010 & Landslide & 2 & 204 & 130 & 130 \\
\hline 2011 & Flood & 2 & 62 & 110 & 12810 \\
\hline 2012 & Earthquake & 1 & 73 & 2 & 237 \\
\hline 2012 & Flood & 6 & 149 & 311 & 51150 \\
\hline 2012 & Landslide & 3 & 111 & 46 & 46 \\
\hline 2013 & Earthquake & 1 & 18 & 141 & 3531 \\
\hline 2013 & Flood & 4 & 113 & 2 & 17097 \\
\hline 2013 & Landslide & 1 & 24 & --- & 1000 \\
\hline 2014 & Flood & 2 & 512 & 135 & 150135 \\
\hline 2015 & Earthquake & 2 & 115 & 58092 & 93132 \\
\hline 2015 & Landslide & 4 & 324 & --- & 33635 \\
\hline 2016 & Flood & 5 & 91 & 10 & 3010 \\
\hline
\end{tabular}

\section{CONCLUSION}

The whole study encountered different disasters and their effects on human life in Pakistan and surrounding. The targeted disasters are counting earthquake, flood and landslide. In case of flood, the minimum occurrence is one while maximum is three times. Minimum deaths are 636 while maximum are 2113. In case of earthquake, the minimum occurrence is one while maximum are three. Maximum deaths are 73338. In landslide, the minimum occurrence is one while maximum is three. Minimum deaths are 12 while maximum are 153 . In the period of sixteen years, occurrences, total effects and total deaths against the said disaster types have been analyzed. A one way ANNOVA between disaster groups analysis of variance is conducted to explore the impacts of all disaster types. There is statistically similarity between all groups at $\mathrm{p}=0.01 \& 0.05$. In a nutshell, the occurrence of both earthquake and landslides are same, while flood occurrence rate is considerably higher than earthquake and landslide. Though the intensity and occurrences rate of all disasters are dissimilar, but the average loss of lives in above considered disasters are approximately the same in all groups. Furthermore, the occurrence of both earthquake and landslides are same while, flood have occurrences rate is considerably higher than earthquake and landslide. Though the intensity and occurrences rate of these disasters are dissimilar but average loss of lives in above considered disasters are approximately the same. The disaster patterns and analysis can be helpful for disaster management authorities in disaster management processes.

\section{REFERENCE}

[1] Yaqub, M., Eren, B., Doğan, E. 2015. Disasters in Asia and the Pacific: 2015 Year in Review. Flood Causes, Consequences and Protection Measures in Pakistan. Disaster Science and Engineering, 1(1), 8-16.

[2] Swathi, J.M. 2015. Natural Disasters and Economic Growth in Pakistan: An Enquiry into the Floods Related Hazards' Triad. The profile of disaster risk of Pakistan and institutional response. Emergency and Disaster Reports, 2 (1).

[3] Khan H., Khan, A. Kazmi, A.A. 2008. The Culture of Disaster Risk Reduction and Pakistan.

[4] Sardar, A., Javed, S.A., Amirud-Din, R. 2016. Natural hazards and disaster management in Pakistan. Pakistan Institute of Development Economics, 1, 2-12.

[5] http://www.emdat.be/advanced_search/index.html 